Brazilian Journal
of Chemical
Engineering

ISSN 0104-6632

Printed in Brazil

www.abeq.org.br/bjche

Vol. 26, No. 01, pp. 99 - 111, January - March, 2009

\title{
INTELLIGENT TECHNIQUES FOR SYSTEM IDENTIFICATION AND CONTROLLER TUNING IN pH PROCESS
}

\author{
K. Valarmathi ${ }^{1 *}$, D. Devaraj ${ }^{1}$ and T. K. Radhakrishnan ${ }^{2}$ \\ ${ }^{1}$ Department of Electrical and Electronics Engineering, Arulmigu Kalasalingam \\ College of Engineering, Tamilnadu, India. \\ E-mail: krvalarmathi@yahoo.co.in, E-mail: deva230@yahoo.com \\ ${ }^{2}$ Department of Chemical Engineering, National Institute of Technology, \\ Trichy, Tamilnadu, India. E-mail: radha@nitt.edu
}

(Submitted: February 1, 2007 ; Revised: March 4, 2008 ; Accepted: April 21, 2008)

\begin{abstract}
This paper presents an application of Artificial Neural Network (ANN) and Genetic Algorithm (GA) for system identification for controller tuning in a $\mathrm{pH}$ process. In this paper, the ANN based approach is applied to estimate the system parameters. Once the variations in parameters are identified frequently, GA optimally tunes the controller. The simulation results show that the proposed intelligent technique is effective in identifying the parameters and has resulted in a minimum value of the Integral Square Error, peak overshoot and minimum settling time as compared to conventional methods. The experimental results show that their performance is superior and it matches favorably with the simulation results.

Keywords: System Identification; PID controller; Genetic Algorithm; Artificial Neural Network; pH process.
\end{abstract}

\section{INTRODUCTION}

The $\mathrm{pH}$ control finds wide applications in process industries. The $\mathrm{pH}$ process is a non-linear dynamic system and an extremely complex and challenging control problem in process industries (Kulkarni and Deshpande, 1991). The extensive applications of the $\mathrm{pH}$ process in industry merit the study of the control of these processes. The Proportional Integral Derivative (PID) controller has been widely used in the $\mathrm{pH}$ process for many years. Tuning of PID controller parameters is necessary for the satisfactory operation of the process. Traditionally, the PID controller parameters are evaluated using ZieglerNichols (ZN) (Astrom and Hagglund, 2001) and Cohen Coon (CC) (Schei, 1994; Shinskey, 1996) methods. In both these methods, the parameters of the controller are obtained for an operating point where the model can be considered linear. The dynamic characteristics of most of the industrial processes exhibit nonlinear behavior and vary with time. This implies that there is sub-optimal tuning when a process operates outside the validity zone of the model. Internal Model Control (IMC) (Morari and Zufiriou, 1987) overcomes the above said problem, but its design calculations could be complicated for a higher order process.

In general, plant parameters change due to ageing of the plant or changes in the load. Also, the process non-linearities and time dependent characteristics cause a significant change in the dynamic parameters of the process, which necessitates identification of the process model under different operating conditions so that controller design can be effected (Dionisio and Pinto, 2005). Here, the plant model is identified periodically and the changes in its dynamic characteristics are observed. This offers a great advantage over the conventional controller tuning methods, which use the plant model at the nominal operating conditions. In conventional

*To whom correspondence should be addressed 
identification methods, a model structure is selected and the parameters of the model are calculated by optimizing an objective function using an optimization technique. A variety of model structures are available to assist in modeling a system. The various models are categorized into linear and nonlinear models. The generally used linear models are Auto Regressive with eXogenous inputs (ARX), Auto Regressive with Moving Average with eXogenous inputs (ARMAX) and Output Error (OE) models. The nonlinear models include Hammerstein, Weiner model and Nonlinear Auto Regressive with Moving Average with eXogenous inputs (NARMAX). The conventional parameter identification methods namely least squares (Rad and Lo, 1997) and maximum likelihood method (Ljung, 1999) often fail in the search for a global optimum in the search space. Further, they require a large set of input/output data from the system.

Intelligent techniques overcome the difficulties and limitations encountered by the conventional approaches for system identification and controller tuning. These techniques explore the potential for creating intelligent systems by modeling the computational process of biological organisms. The constituents of this technique include Artificial Neural Network (Wasserman, 1989), Fuzzy Logic (Ross, 1995) and Genetic Algorithm (Goldberg, 1989). Narendra and Parthasarathy (1990) proposed ANN to identify the complex, nonlinear, multidimensional model. Genetic algorithm (Passino, 1996) is a general-purpose optimization algorithm based on the mechanics of natural selection and genetics. Kristinsson and Dumont (1992) proposed GA to identify plants with either minimum phase or non-minimum phase characteristic and un-modeled dynamics. Zibo and Naghdt (1995) applied genetic algorithms to identify the parameters of the Multi Input and Multi Output (MIMO) system that is assumed to have an Auto Regressive with Moving Average Exogenous (ARMAX) structure.

$\mathrm{Lu}$ and Basar (1995) presented the standard GAbased estimation scheme in a neural network framework, which ensure a good approximation for the system nonlinearity. Dangprasert and Avatchanakorn (1995) employed GA for on-line parameter identification and controller tuning in load frequency control of a power system. Vlachos et al. (1999) proposed a GA-based design strategy for offline PID controller tuning in linear systems. Mwembeshi and Kent (2004) proposed a GA-based Internal Model Control (IMC) strategy for a $\mathrm{pH}$ process. In this paper, an ANN-based approach has been applied to estimate the changes in the parameters of the system and a GA-based approach is used to identify the optimal PID controller parameters in a $\mathrm{pH}$ process.

\section{pH PROCESS}

The $\mathrm{pH}$ is the measurement of the acidity or alkalinity of a solution. The $\mathrm{pH}$ process consists of neutralization of two monoprotic reagents of a weak acid (acetic acid) and a strong base (sodium hydroxide). The method implements mass balances for components called reaction invariants of the Continuous Stirred Tank Reactor (CSTR) solution. As shown in Figure 1, the CSTR has two inlet streams: the influent process stream and the titrating stream, with one effluent stream at the output. The model of the $\mathrm{pH}$ neutralization process used in this work follows that proposed by McAvoy et al. (1972) and is given below.

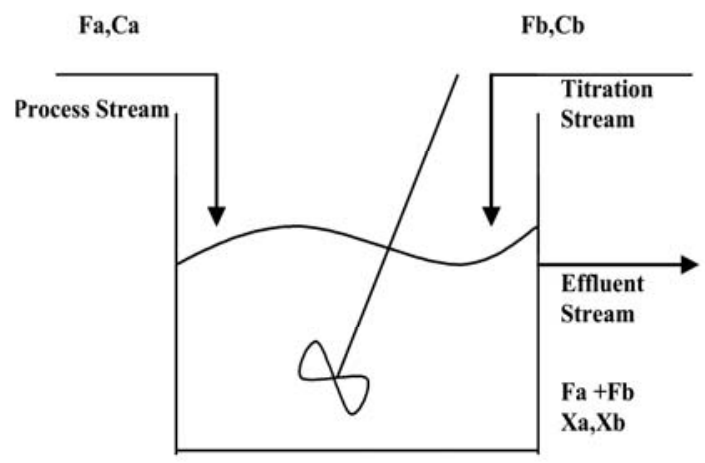

Figure 1: pH neutralization process

Assumption of perfect mixing is general in the modeling of $\mathrm{pH}$ processes. Material balances in the reactor can be given by

$$
\begin{aligned}
& \mathrm{V} \frac{\mathrm{dx}_{\mathrm{a}}}{\mathrm{dt}}=\mathrm{F}_{\mathrm{a}} \mathrm{C}_{\mathrm{a}}-\left(\mathrm{F}_{\mathrm{a}}+\mathrm{F}_{\mathrm{b}}\right) \mathrm{X}_{\mathrm{a}} \\
& \mathrm{V} \frac{\mathrm{dx_{b }}}{\mathrm{dt}}=\mathrm{F}_{\mathrm{b}} \mathrm{C}_{\mathrm{b}}-\left(\mathrm{F}_{\mathrm{a}}+\mathrm{F}_{\mathrm{b}}\right) \mathrm{x}_{\mathrm{b}}
\end{aligned}
$$

where $F_{a}$ is the flow rate of the influent stream, $F_{b}$ is the flow rate of the titrating stream, $\mathrm{C}_{\mathrm{a}}$ is the concentration of the influent stream, $\mathrm{C}_{\mathrm{b}}$ is the concentration of the titrating stream, $x_{a}$ is the concentration of the acid solution, $x_{b}$ is the 
concentration of the basic solution and $\mathrm{V}$ is the volume of the mixture in the CSTR. The above mathematical equations describe how the concentration of the acidic and basic components, $\mathrm{x}_{\mathrm{a}}$ and $\mathrm{x}_{\mathrm{b}}$ change dynamically with time subject to the input streams, $F_{a}$ and $F_{b}$. The reaction between $\mathrm{HAC}$ and $\mathrm{NaOH}$ :

$$
\mathrm{H}_{2} \mathrm{O} \quad \mathrm{H}^{+} \mathrm{H}^{+}
$$

$\mathrm{HAC} \quad \mathrm{H}^{+} \Rightarrow \mathrm{AC}^{-}$

$\mathrm{NaOH} \quad \mathrm{Na}^{+} \underset{F}{\mathrm{~F}} \mathrm{H}^{-}$

Invoking the electroneutrality condition, the sum of the ionic charges in the solution must be zero.

$$
\left[\mathrm{Na}^{+}\right]+\left[\mathrm{H}^{+}\right]=\left[\mathrm{AC}^{-}\right]+\left[\mathrm{OH}^{-}\right]
$$

The $[\mathrm{X}]$ denotes the concentration of the $\mathrm{X}$ ion. The equilibrium relations also hold for water and acetic acid

$\mathrm{K}_{\mathrm{a}}=\frac{\left[\mathrm{AC}^{-}\right]\left[\mathrm{H}^{+}\right]}{[\mathrm{HAC}]}$

where $\mathrm{X}_{\mathrm{a}}=[\mathrm{HAC}]+\left[\mathrm{AC}^{-}\right]$and $\mathrm{X}_{\mathrm{b}}=\left[\mathrm{Na}^{+}\right]$. Use of Equations (6) and (7) gives:

$\left[\mathrm{H}^{+}\right]^{3}+\left[\mathrm{H}^{+}\right]^{2}\left\{\mathrm{~K}_{\mathrm{a}}+\mathrm{X}_{\mathrm{b}}\right\}+$

$\left[\mathrm{H}^{+}\right]\left\{\mathrm{K}_{\mathrm{a}}\left(\mathrm{X}_{\mathrm{b}}-\mathrm{X}_{\mathrm{a}}\right)-\mathrm{K}_{\mathrm{w}}\right\}-\mathrm{K}_{\mathrm{w}} \mathrm{K}_{\mathrm{a}}=0$

Let $\mathrm{pH}=-\log _{10}\left[\mathrm{H}^{+}\right]$and $\mathrm{pK}_{\mathrm{a}}=-\log _{10} \mathrm{~K}_{\mathrm{a}}$. The titration curve is given by

$\mathrm{X}_{\mathrm{b}}+10^{-\mathrm{pH}}-10^{-\mathrm{pH}^{-14}}-\frac{\mathrm{X}_{\mathrm{a}}}{1+10^{\mathrm{pKa}-\mathrm{pH}}}=0$

where $\mathrm{K}_{\mathrm{a}}$ and $\mathrm{K}_{\mathrm{w}}$ is the dissociation constant of acetic acid at $5^{\circ} \mathrm{C} \quad\left(\mathrm{K}_{\mathrm{a}}=1.778 \times 10^{-5} \quad\right.$ and $\mathrm{K}_{\mathrm{W}}=10^{-14}$ ). Eq.(9) is the strictly static nonlinear relation between the states $\mathrm{X}_{\mathrm{a}}, \mathrm{X}_{\mathrm{b}}$ and the output $\mathrm{pH}$ variable, which manifests itself as the familiar titration curve of the neutralization process.

\section{STRATEGY FOR SYSTEM IDENTIFICATION AND CONTROLLER TUNING}

System identification is the type of experimental modeling performed for the controller design, when sufficient theoretical modeling is not available. The proposed strategy for designing the self-tuning schemes is to estimate the process parameters and to adjust the controller settings based on current parameter estimates. The block diagram representation of parameter estimation and controller tuning is shown in Figure 2.

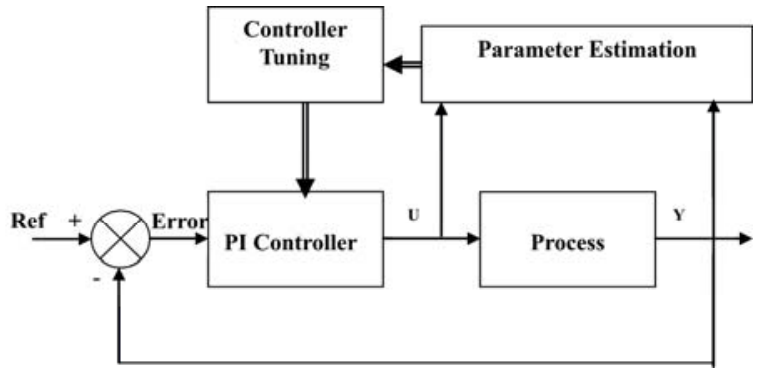

Figure 2: ANN based Parameter Estimation and GA based Controller Tuning

Generally the parameter estimation is done using the Least Square (LS) technique. This LS estimator looks for the optimum by using the gradient technique. System identification is the prerequisite for analyzing the nonlinear process. In this paper, ANN is used for system identification. First, a suitable model of the system is selected and ANN is applied to identify the parameters of the selected model. As the plant model is identified periodically, the changes in its dynamic characteristics can be observed. Generally, for the parameter estimation, the system $(\mathrm{G})$ is excited with a step function as an input, which is shown in Figure 3.

In this figure, $\mathrm{G}$ is an unknown system and $\mathrm{H}$ is an assumed model. The system parameters can be obtained by minimizing the error function $\mathrm{e}(\mathrm{k})$, where $\hat{y}(k)$ is the predicted value of output based on unknown parameters and $\mathrm{y}(\mathrm{k})$ is the actual output.

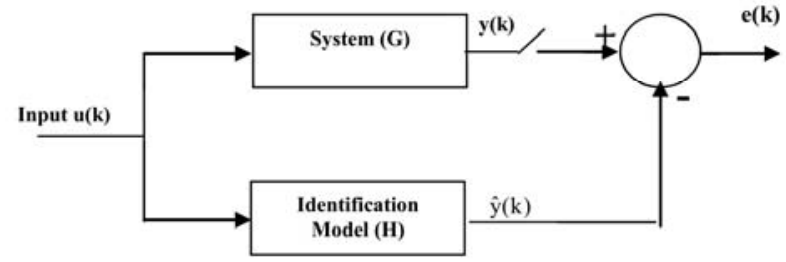

Figure 3: Structure of parameter estimation 
The next step after system identification is the tuning of the PI controller, whose transfer function is given by

$\mathrm{G}_{\mathrm{c}}(\mathrm{s})=\mathrm{K}_{\mathrm{p}}+\frac{\mathrm{K}_{\mathrm{i}}}{\mathrm{s}}$

where $\mathrm{K}_{\mathrm{p}}$ is proportional gain and $\mathrm{K}_{\mathrm{i}}$ is integral gain. The performance of the closed loop system is defined by the performance criteria of Integral Square Error for controller (ISE(cont)), Over Shoot (OS) and Settling Time (ST) of the transient response.

The Integral Square Error squares the magnitude of error with respect to time. The overshoot is the difference between the maximum value of the output response and the steady state value and the settling time is the time for the response to stay within the specified percentage of its final value. In this work, the problem of controller tuning is formulated as an optimization problem. The objective function of the controller is to minimize the integral square error, peak overshoot, rise time and settling time of the transient response. Mathematically, this is written as

$\mathrm{F}=\mathrm{w}_{1} \mathrm{~F}_{\mathrm{ISE}(\text { cont })}+\mathrm{w}_{2} \mathrm{~F}_{\mathrm{OS}}+\mathrm{w}_{3} \mathrm{~F}_{\mathrm{ST}}$

where $\mathrm{w}_{1}, \mathrm{w}_{2}$ and $\mathrm{w}_{3}$ are the weight factors for the integral square error, overshoot and settling time respectively. The weight factors are varied between 0 and 1 to get the optimal system response. Gradientbased conventional methods are not good enough to solve this problem and a global optimization technique like genetic algorithm is well suited for this kind of problems.

\section{DEVELOPMENT OF ANN FOR SYSTEM IDENTIFICATION}

System Identification allows building mathematical models of a dynamic system based on measured data. It is done by adjusting parameters within a given model until its output coincides as much as possible with the measured output. The assessment of model quality is typically based on how the models perform when they attempt to reproduce the measured data.

In the identification framework, the $\mathrm{pH}$ process can be represented in discrete input-output form by the identification structure:

$$
\begin{aligned}
& \hat{y}[k]=\hat{g}\left[y(k-1), \ldots, y\left(k-n_{a}\right),\right. \\
& \left.u\left(k-n_{k}\right), \ldots u\left(k-n_{b}-n_{k}+1\right)\right]
\end{aligned}
$$

where $\hat{y}[k]$ is the one-step ahead prediction of the output, $\hat{g}$ is the neural network model, $u(\cdot)$ are delayed inputs to the system and $n_{a}, n_{b}, n_{k}$ are system order and delay, respectively. This is essentially a one-step ahead prediction structure in past inputs and outputs to predict the current output. The regressor structure for this network is given by:

$$
\begin{aligned}
& \varphi(k)=\left[\hat{y}(k-1), \ldots, \hat{y}\left(k-n_{a}\right),\right. \\
& \left.u\left(k-n_{k}\right), \ldots, u\left(k-n_{b}-n_{k}-1\right)\right]
\end{aligned}
$$

Depending on the choice of the regression vector, different model structures emerge. At every instant, the predicted output is parameterized in terms of network weights $\Theta$ by:

$$
\mathrm{y}(\mathrm{k}, \Theta)=\mathrm{g}(\varphi(\mathrm{k}), \Theta)
$$

Artificial Neural Network (ANN) is used in this work for system identification. The data required to develop the ANN model for system identification are collected by conducting experiments in the laboratory grade $\mathrm{pH}$ process and through MATLAB simulation. The collected data is divided into training and test data. The sampling instant $\mathrm{k}$ is equivalent to $t$ and the neural network structure used here is shown in Figure 4.

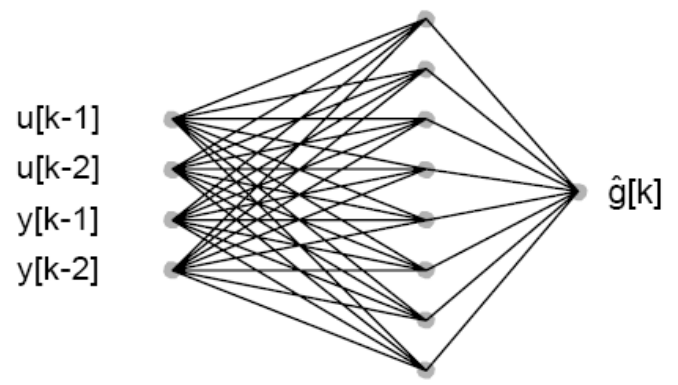

Figure 4: Architecture of the neural network

Network training is first carried out offline in batch form using the Levenberg-Marquadt optimization. The algorithm essentially seeks to minimize the prediction error over the training data set. The input and output data sets used for training are obtained by adding a random generator with step input and then applying this to the trained to minimize the cost function 
$J=\frac{1}{2 N} \sum_{k=1}^{N}[y(k)-\hat{y}(k)]^{T}[y(k)-\hat{y}(k)]$

where

$\mathrm{e}(\mathrm{k})=[\mathrm{y}(\mathrm{k})-\hat{\mathrm{y}}(\mathrm{k})]$

Similarly, testing data are generated through the experimental setup and MATLAB simulation to minimize the cost function.

\section{GA IMPLEMENTATION}

GA has become increasingly popular in recent years in science and engineering disciplines. There are three important issues to be addressed while applying GA to solve an optimization problem:

a) Problem Representation

b) Formation of the fitness function and

c) Genetic operators

\section{a) Problem Representation}

While solving an optimization problem using GA, each individual in the population represents a candidate solution. For tuning a PID controller, the elements of the solution consist of proportional gain $\left(\mathrm{K}_{\mathrm{p}}\right.$ ) and integral gain $\left(\mathrm{K}_{\mathrm{i}}\right)$. In this work, binary strings are used to encode the variables. A typical chromosome in the GA population for PID tuning is given below:

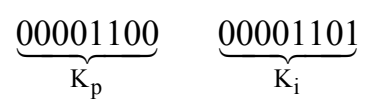

\section{b) Formation of Fitness Function}

The next important consideration is the formation of the fitness function. The performance of each individual in the population is evaluated according to its 'fitness', which is defined as the non-negative figure of merit to be maximized. It is associated directly with the objective function value. The values of the Integral Square Error (ISE), settling time (st) and peak overshoot (po) in Eq. (11) are calculated from the step response of the simulated system. These values are used to calculate the fitness function of the individuals.

During the GA-run, it searches for a solution with maximum fitness function value. Hence, the minimization objective function given by (11) is transformed to a fitness function (f) to be maximized as,

$\mathrm{f}=\mathrm{K} / \mathrm{F}$

where $\mathrm{K}$ is a large constant. This is used to amplify $(1 / F)$, the value of which is usually small, so that the fitness value of the chromosome will be in a wider range.

\section{c) Genetic Operators}

Genetic algorithm is governed by the three operators selection, crossover and mutation. The selection of individuals to produce successive generations plays an important role in GA. Reproduction comprises forming a new population, usually with the same population size, by selecting from members of the current population following a particular scheme. The higher the fitness, the more likely it is that the chromosomes will be selected for next generation. There are several strategies for selecting the individuals, e.g., roulette-wheel selection, ranking methods and tournament selection. In this paper, tournament selection is used to generate the new population. In the tournament selection the individuals are selected at random from the population and the best individual is inserted into the new population for further genetic processing. This procedure is repeated until the mating pool is filled. Tournaments are often held between pairs of individuals, although larger tournaments can be held. Once the selection process is completed, the crossover is applied. The crossover operator is mainly responsible for the global search property of the GA. Crossover basically combines substructures of two parent chromosomes to produce new features, with the specified probability. In this paper two-point crossover is applied during identification and controller tuning. In the two-point crossover, two crossover sites are chosen and offspring are created by swapping the bits between the chosen crossover sites. Figure 5 illustrates the two point cross over clearly. The final operator in Genetic Algorithm is mutation. The mutation operator is used to inject new genetic material into the population. Mutation randomly alters a variable with a small probability. For binary encoding bitwise mutation is preferred, which switches a few randomly chosen bits from 1 to 0 or 0 to 1 with the mutation probability. The general values of crossover and mutation probabilities are in the range of 0.6-0.9 and 0.001-0.1 respectively. 


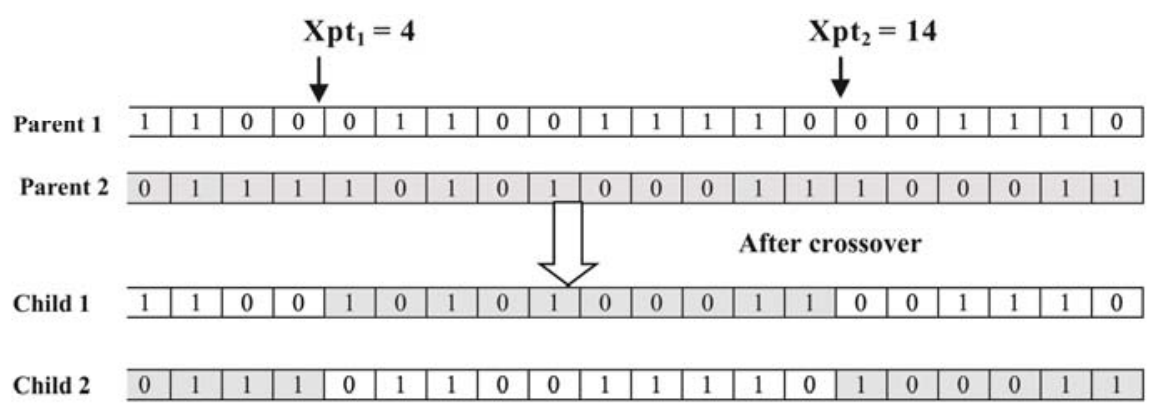

Figure 5: Two-point crossover

\section{RESULTS AND DISCUSSION}

This section presents the details of the development of a neural network based model for system identification and GA-based PI controller tuning for the $\mathrm{pH}$ process. System identification and controller tuning algorithm were evaluated on a simulated $\mathrm{pH}$ process. Next, the same algorithms were applied to a laboratory grade $\mathrm{pH}$ process. The ANN and GA code were written in MATLAB and executed on a PC with Pentium IV processor. The design details and the performance of the controller are given below.

\section{Simulation Results}

The $\mathrm{pH}$ process was simulated based on the Equations (1) and (2) using MATLAB Simulink. The parameters of the $\mathrm{pH}$ process are $\mathrm{pH}$ model simulated using MATLAB Simulink is shown in Figure 6. Step signal is used as the input to the system. Uniformly distributed noise is added to the step input through a uniform random generator. This is done to cause nonlinear distortion due to the dead zone nonlinearity in the $\mathrm{pH}$ process.

Initially, 5000 samples were generated from MATLAB simulation. 2000 samples are taken as training data set and 2800 samples are considered as testing data set. Figure 7 and Figure 8 show the training and testing data generated using MATLAB Simulink.

Next, the different linear model structures are generated with minimization of Mean Square Error. Figure 9 shows the ARX structure of $\left[n_{a} n_{b} n_{k}\right]=\left[\begin{array}{ll}2 & 2\end{array}\right.$ $1]$, where $n_{a}$ is equal to the number of poles and $n_{b}$ is the number of zeros, while $n_{k}$ is the pure time-delay in the system. Similarly, Figure 10 and Figure 11 show the ARMAX structure of $\left[n_{a} n_{b} n_{c} n_{k}\right]=\left[\begin{array}{lll}6 & 6 & 6\end{array}\right.$

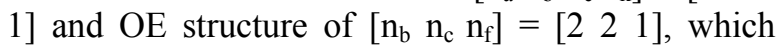
show the minimum of MSE. The conventional identification techniques cannot identify the full dynamics of the non-linear $\mathrm{pH}$ process. To avoid this problem, neural network based system identification is applied and the results are obtained. Figures 12-14 shows the performance of the NARX model, structure of $\left[n_{a} n_{b} n_{k}\right]=\left[\begin{array}{lll}3 & 3 & 1\end{array}\right]$. Figure 12 illustrates the response of prediction error and Figure 13 illustrates the auto-correlation and cross-correlation response of NARX structure. Figure 14 represents the fitness function of MSE, which is $3.6 \times 10^{-5}$.

Different structure models were checked for Mean Square Error and the results are shown in Table.2. From the Table, it is found that the NARX model structure of $\left[\begin{array}{lll}3 & 3 & 1\end{array}\right]$ gives the minimum MSE compared to other structures. Similarly, NARX structure of [ [ $\left.\begin{array}{lll}6 & 6 & 1\end{array}\right]$ of experimental data gives the minimum MSE compared to other structures.

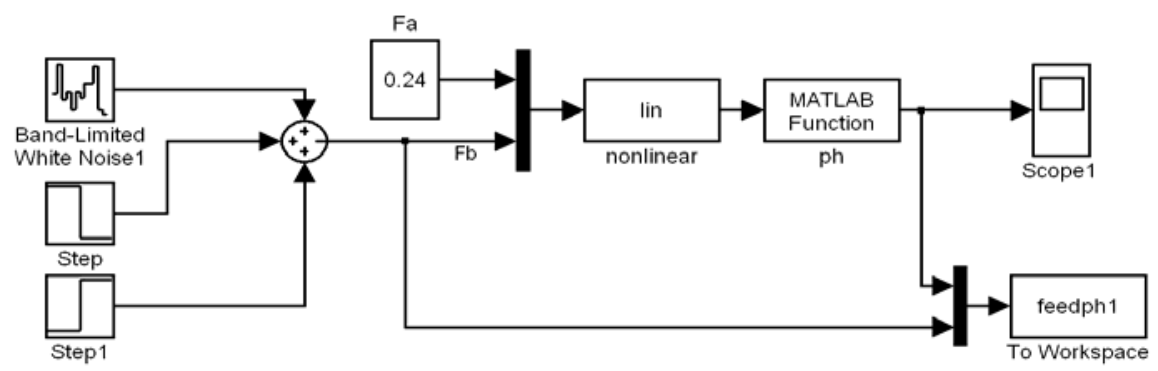

Figure 6: Simulation of $\mathrm{pH}$ model 
Table 1: Model parameters for the $\mathrm{pH}$ process

\begin{tabular}{|l|l|c|}
\hline Symbols & Description & Value \\
\hline $\mathrm{V}$ & Volume of the Continuous Stirred Tank Reactor & $7.4 \mathrm{~L}$ \\
$\mathrm{~F}_{\mathrm{a}}$ & Flow rate of the influent stream & $0.24 \mathrm{~L} / \mathrm{min}$ \\
$\mathrm{F}_{\mathrm{b}}$ & Flow rate of the titrating stream & $0-0-0.8 \mathrm{~L} / \mathrm{min}$ \\
$\mathrm{C}_{\mathrm{a}}$ & Concentration of the influent stream & $0.2 \mathrm{~mol} / \mathrm{L}$ \\
$\mathrm{C}_{\mathrm{b}}$ & Concentration of the titrating stream & $0.1 \mathrm{~mol} / \mathrm{L}$ \\
\hline
\end{tabular}

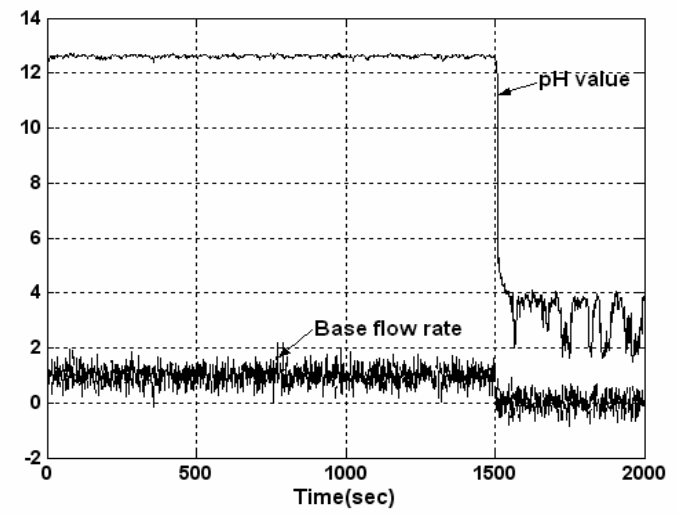

Figure 7: Training data from MATLAB Simulink

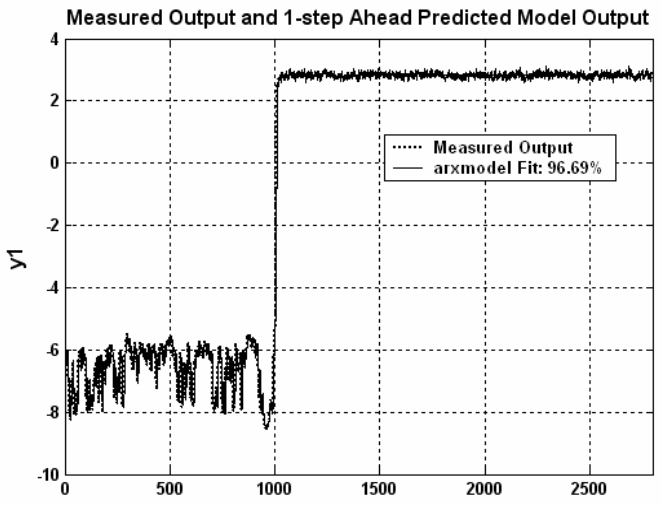

Figure 9: Validation of the ARX structure for simulated $\mathrm{pH}$ process

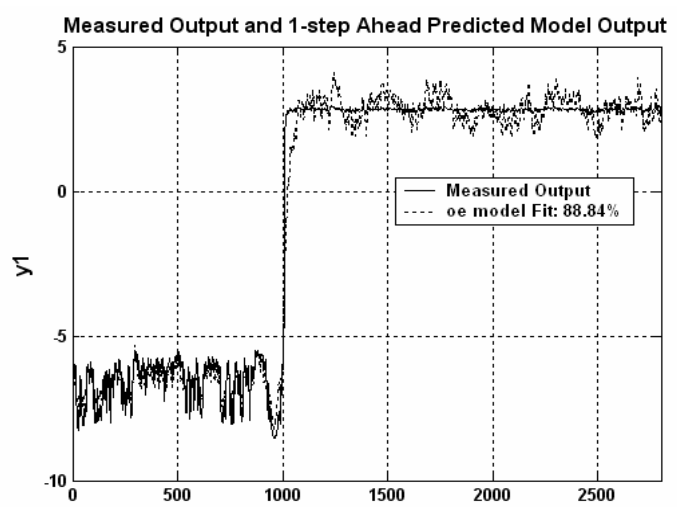

Figure 11: Validation of the $\mathrm{OE}$ structure for simulated $\mathrm{pH}$ process

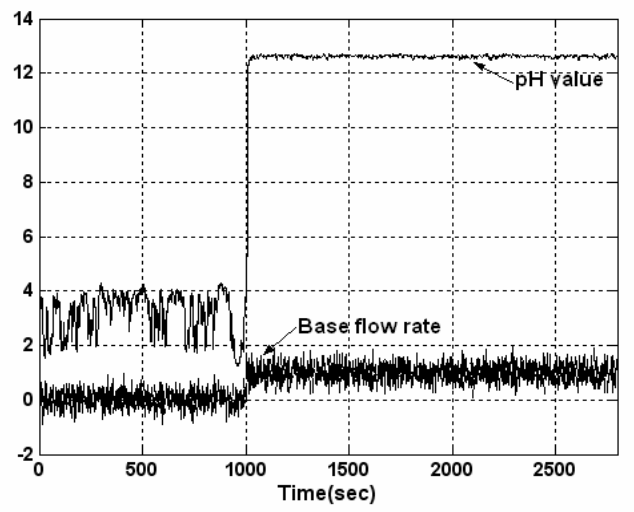

Figure 8: Testing data from MATLAB Simulink

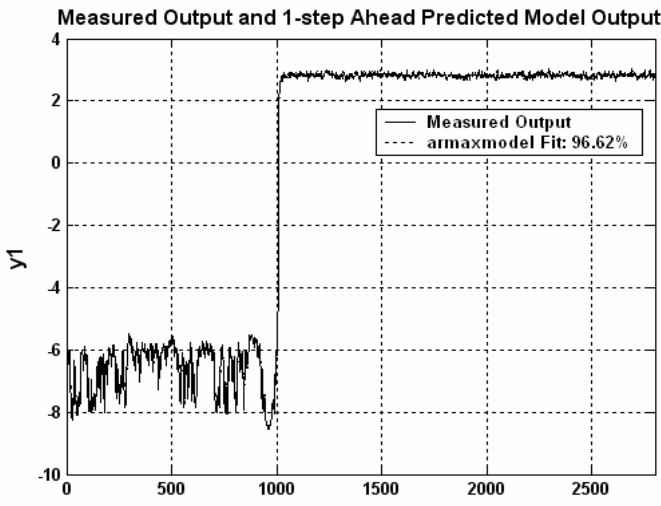

Figure 10: Validation of the ARMAX structure for simulated $\mathrm{pH}$ process
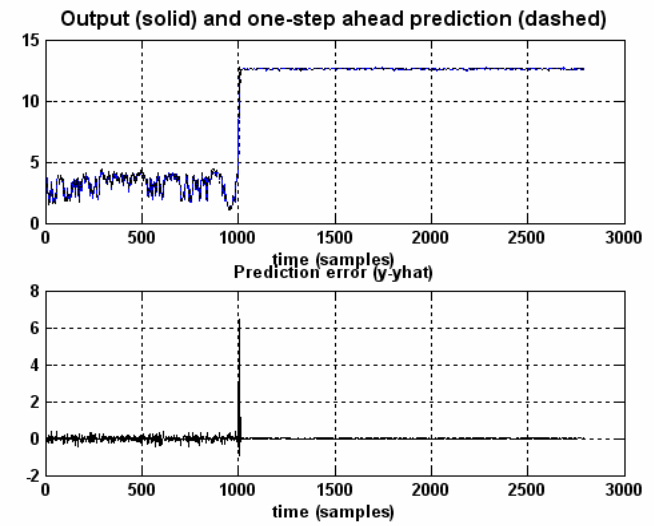

Figure 12: Performance of Prediction error of Simulated $\mathrm{pH}$ process using NARX structure 


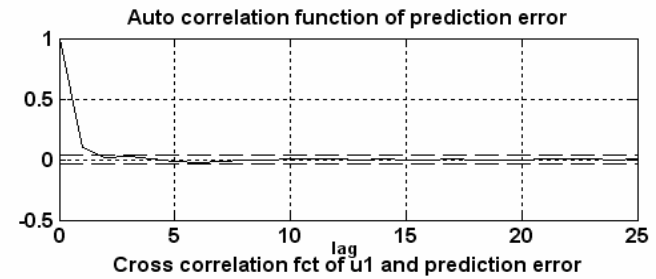

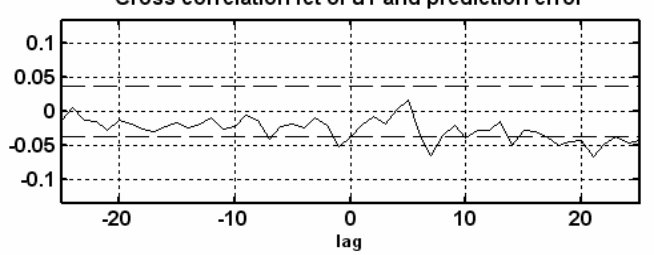

Figure 13: Auto-correlation and cross-correlation function for simulated data using NARX structure

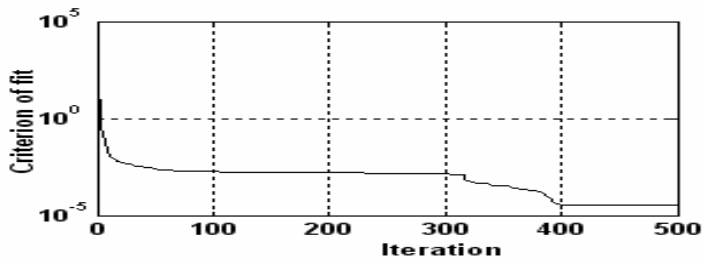

Figure 14: Fitness curve for NARX structure

Table 2: Comparison of the Models

\begin{tabular}{|c|c|c|c|c|c|c|c|}
\hline Model & $\mathbf{n}_{\mathrm{a}}$ & $\mathbf{n}_{\mathbf{b}}$ & $\mathbf{n}_{\mathrm{c}}$ & Nf & $\mathbf{n}_{\mathrm{k}}$ & \begin{tabular}{|c|} 
MSE for \\
Simulated data \\
\end{tabular} & $\begin{array}{c}\text { MSE for Real } \\
\text { data }\end{array}$ \\
\hline \multirow[t]{5}{*}{ ARX } & 1 & 1 & - & - & 1 & \begin{tabular}{l|l|}
0.0167 \\
\end{tabular} & 0.0432 \\
\hline & 2 & 2 & - & - & 1 & 0.0165 & 0.043 \\
\hline & 3 & 3 & - & - & 1 & 0.0165 & 0.0432 \\
\hline & 4 & 4 & - & - & 1 & 0.0166 & 0.042 \\
\hline & 6 & 6 & - & - & 1 & 0.0166 & 0.039 \\
\hline \multirow[t]{5}{*}{ ARMAX } & 1 & 1 & 1 & - & 1 & 0.017 & 0.043 \\
\hline & 2 & 2 & 2 & - & 1 & 0.017 & 0.039 \\
\hline & 3 & 3 & 3 & - & 1 & 0.0174 & 0.04 \\
\hline & 4 & 4 & 4 & - & 1 & 0.0174 & 0.039 \\
\hline & 6 & 6 & 6 & - & 1 & 0.016 & 0.04 \\
\hline \multirow[t]{5}{*}{$\mathrm{OE}$} & - & 1 & 1 & 1 & - & 0.061 & 0.169 \\
\hline & - & 2 & 2 & 1 & - & 0.055 & 0.17 \\
\hline & - & 3 & 3 & 1 & - & 0.059 & 0.18 \\
\hline & - & 4 & 4 & 1 & - & 0.06 & 0.182 \\
\hline & - & 6 & 6 & 1 & - & 0.055 & 0.183 \\
\hline \multirow[t]{5}{*}{ NNARX } & 1 & 1 & - & - & 1 & $2.2^{*} * 10^{-4}$ & $1.74 * 10^{-2}$ \\
\hline & 2 & 2 & - & - & 1 & $5.77 * 10^{-5}$ & $9.42 * 10^{-3}$ \\
\hline & 3 & 3 & - & - & 1 & $3.63 * 10^{-5}$ & $9.39 * 10^{-3}$ \\
\hline & 4 & 4 & - & - & 1 & $2.30 * 10^{-4}$ & $9.35 * 10^{-3}$ \\
\hline & 6 & 6 & - & - & 1 & $5.12 * 10^{-4}$ & $9.02 * 10^{-3}$ \\
\hline \multirow[t]{5}{*}{ NNARMAX } & 1 & 1 & 1 & - & 1 & $3.92 * 10^{-4}$ & $1.8^{*} 10^{-2}$ \\
\hline & 2 & 2 & 2 & - & 1 & $1.19^{*} 10^{-3}$ & $1.51 * 10^{-2}$ \\
\hline & 3 & 3 & 3 & - & 1 & $3.05 * 10^{-3}$ & $1.29 * 10^{-2}$ \\
\hline & 4 & 4 & 4 & - & 1 & $1.18 * 10^{-3}$ & $1.17 * 10^{-2}$ \\
\hline & 6 & 6 & 6 & - & 1 & $2.19 * 10^{-3}$ & $1.04 * 10^{-2}$ \\
\hline
\end{tabular}

From the analysis of system identification, NARX structure is [ $\left[\begin{array}{lll}3 & 3 & 1\end{array}\right]$ and the transfer

function is $\frac{0.2411 Z^{2}+0.0325 Z+0.08908}{1-0.7814 Z^{2}+0.2266 Z-0.3397}$.

Next, the GA-based algorithm is applied to find the optimal parameters of the controller. The objective function in this case is minimization of error, peak overshoot, rise time and settle time. The optimization variables are represented as binary numbers in the GA population. The initial population is randomly generated between the variable's lower and upper limits. Tournament selection is applied to select the members of the new population. The performance of GA for various values of crossover and mutation probabilities in the range of 0.6-1.0 and 0.001-0.1 respectively was evaluated. The best results of the GA are obtained with the following control parameters. 
Number of generations $=20$

Population size $=10$

Crossover probability $=0.8$

Mutation probability $=0.08$

The GA took 12 s to complete the 20 generations. After 20 generations it is found that all the individuals have reached almost the same fitness value. This shows that GA has reached the optimal solution. Figure 15 and Figure 16 represent the feed flow rate of acid and $\mathrm{pH}$ response for the set point 7 . Figure 17 shows the convergence of the proposed GA algorithm. The variation of the fitness during the GA run is for the best case and shows the generation of optimal variables. It can be seen that the fitness value increases rapidly in the first 2 generations of the GA. During this stage, the GA concentrates mainly on finding feasible solutions to the problem. Then the value increases slowly and settles down near the optimum value with most of the individuals in the population reaching that point. The

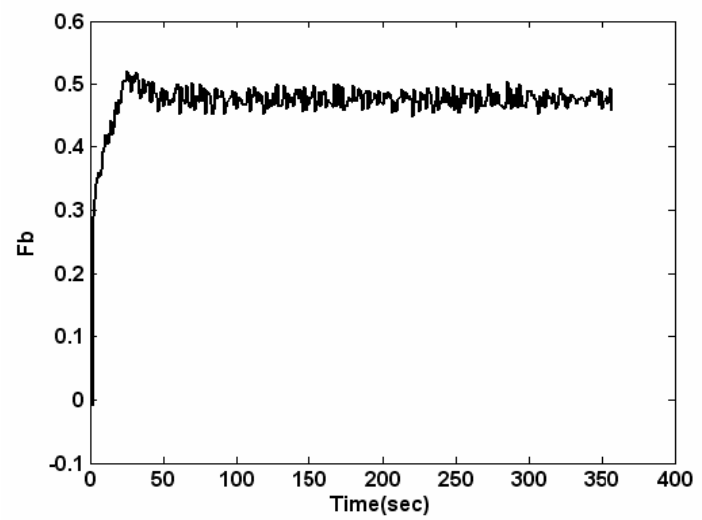

Figure 15: Feed flow rate of $\mathrm{pH}$ process using GA after identification of process for set point 7

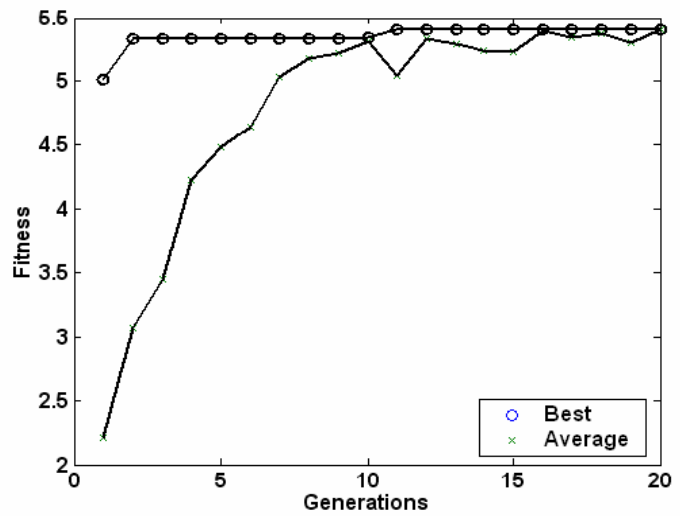

Figure 17: Convergence of GA after Identification of $\mathrm{pH}$ process performance of the various control variables in the $\mathrm{pH}$ process obtained through the proposed GA, compared with the performance results obtained by proposed GA and GA tuning methods for multistages, is shown in Figure 18.

It is clear that the proposed GA tuning produces better controller performance for the $\mathrm{pH}$ process, because it occupies less computation time to reach the optimal solution. For comparison, the parameters of the controller tuned using Ziegler-Nichols and Internal Model Control (IMC) methods are shown. The feed flow rate and performance of the controller using $\mathrm{ZN}$ and IMC for the set point of 7 are shown in Figure 19 and 20. It shows that the control performance using $\mathrm{ZN}$ and $\mathrm{KT}$ has oscillatory response and more peak overshoot and rise time is high at the set point 9 . Overall the performance of the controller is found to be good when it is tuned with the proposed GA.

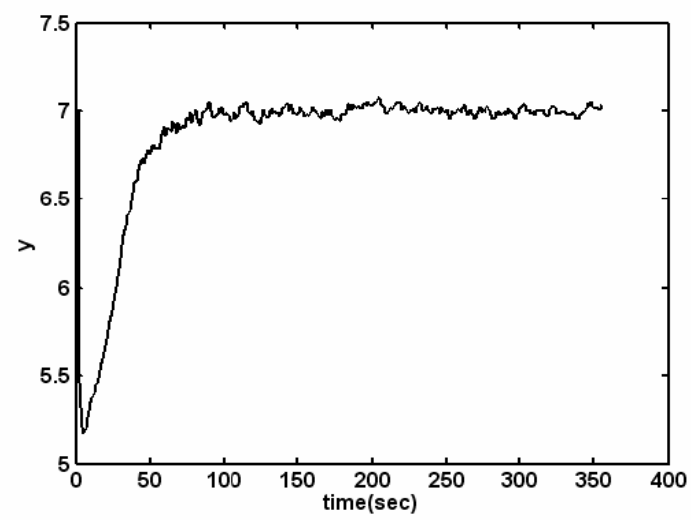

Figure 16: $\mathrm{pH}$ value of $\mathrm{pH}$ process using GA after identification of process for $\mathrm{sp} 7$

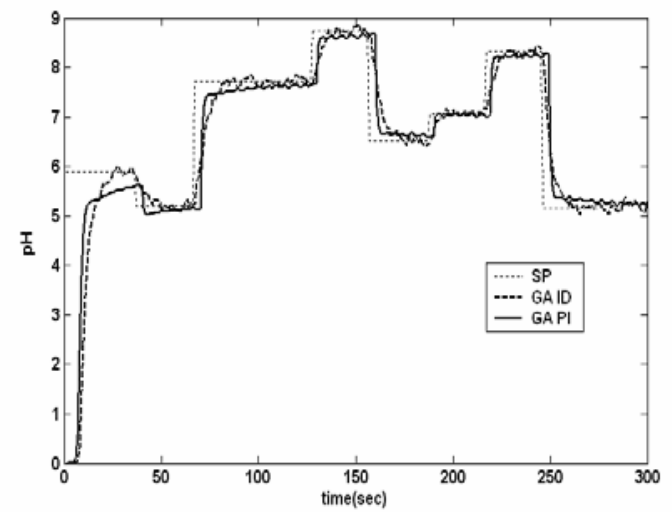

Figure 18: Simulation of GA after identification and GA tuned PI for set point tracking 


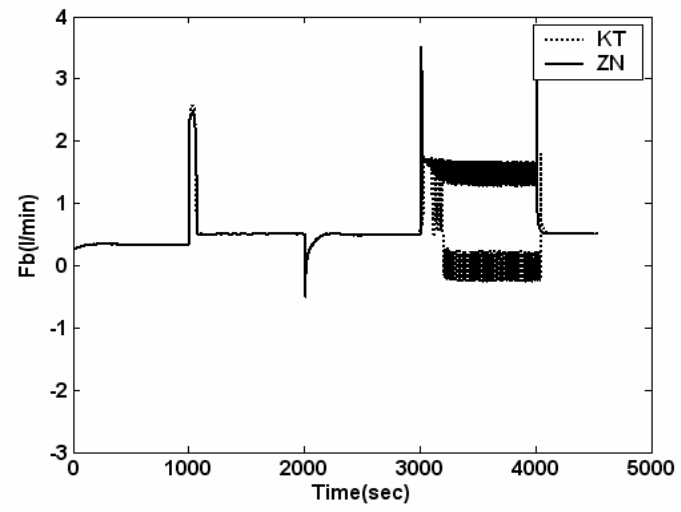

Figure 19: Feed flow rate of $\mathrm{pH}$ process using Kappa Tau and ZN tuning methods

\section{Experimental Results}

In the experimental setup, acetic acid is fed to the reactor with constant flow rate and sodium hydroxide is introduced to the reactor through the pump. Figure 21 shows the $\mathrm{pH}$ process experimental setup. In the real time implementation, the dSPACE processor can be easily interfaced with Simulink and automatically converts the Simulink model into a targeted $\mathrm{C}$ code and downloads it to the designated hardware (dSPACE DS1102) via RTI. To read or write the internal variables of the control system, dSPACE Control Desk provides a user-friendly Graphic User Interface (GUI) environment that enables the user to observe vital data in the system.

From the laboratory scale $\mathrm{pH}$ process the feed flow rate and $\mathrm{pH}$ values were generated and checked with different model structures. Similar to simulated data 5000 data were generated. Figures 22 and 23 show the response of training and testing data generated experimentally. Figures 24 and 25 show

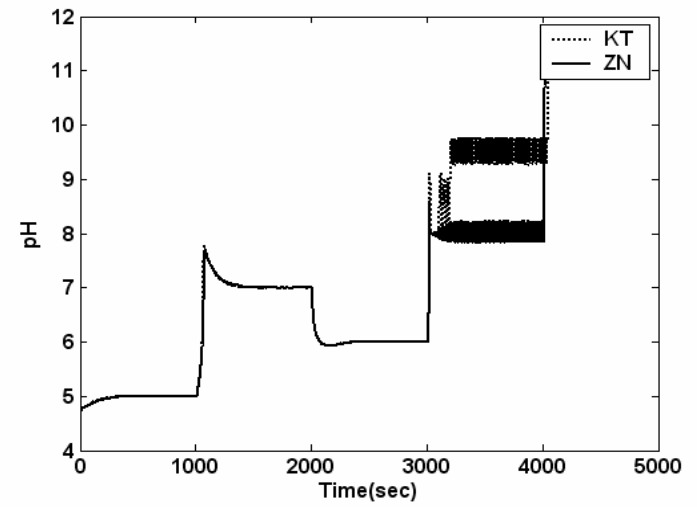

Figure 20: Performance of $\mathrm{pH}$ process using Kappa Tau and ZN tuning methods

the ARX, ARMAX structures of the real data set, which matches favorably with the simulated work.

Similarly, Figures 26 and 27 show the response of the NARX structure [ $\left[\begin{array}{lll}6 & 6 & 1\end{array}\right]$ using the real dataset. Figure 26 illustrates the response of prediction error and Figure 27 shows the histogram of prediction error and parameter values. Figure 28 illustrates the auto- correlation and cross-correlation response of the NARX structure and Figure 29 represents the fitness function of MSE, which is $9.02 \times 10^{-3}$.

In the real time implementation, the parameters of the PI controller are fed to the $\mathrm{pH}$ process via MATLAB Simulink Real-Time Workshop (RTW), Real-Time Interface (RTI) and dSPACE DS1102 floating-point processor. Figures 30 and 32 represent the behavior of the base feed flow rate and $\mathrm{pH}$ response using conventional PI controller and show that the control performance is oscillatory. Figures 31 and 33 show the base flow rate and $\mathrm{pH}$ value using the GA tuned controller. From the figures, the GA tuned PI controller after identification has the minimum MSE of 0.1817.

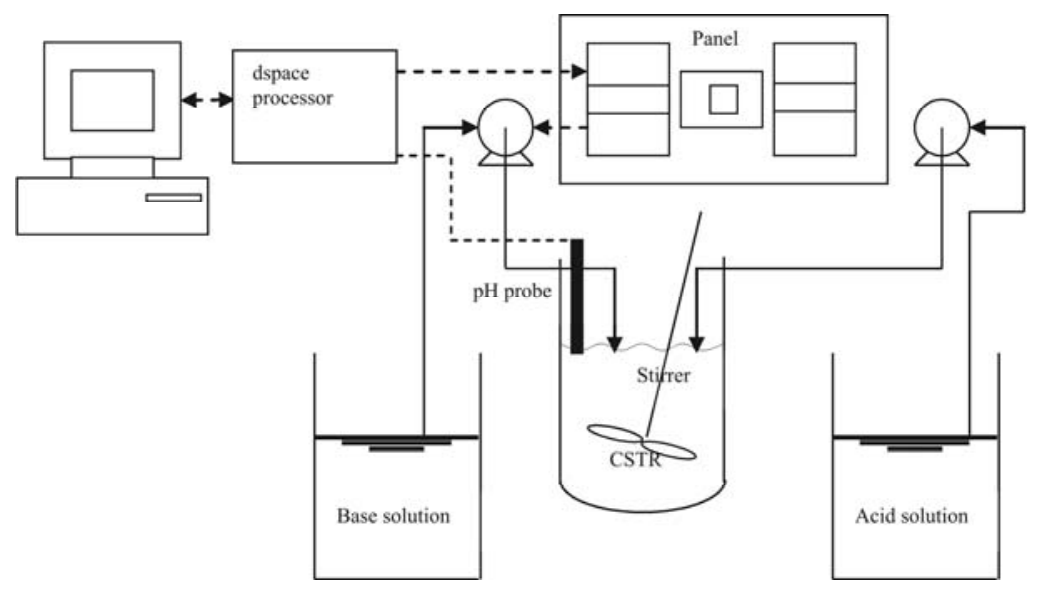

Figure 21: Experimental setup 


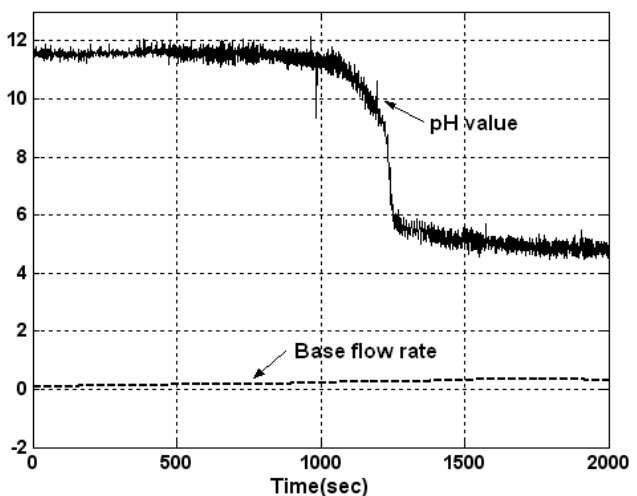

Figure 22: Training data from

Experimental Work

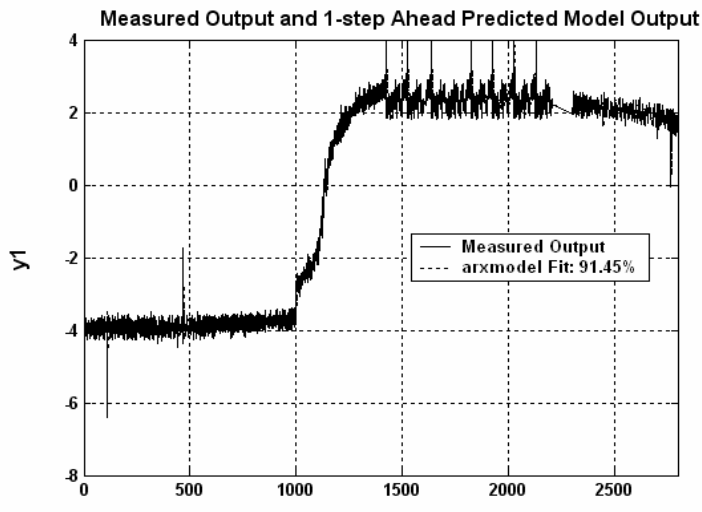

Figure 24: Validation of the ARX structure for Experimental work
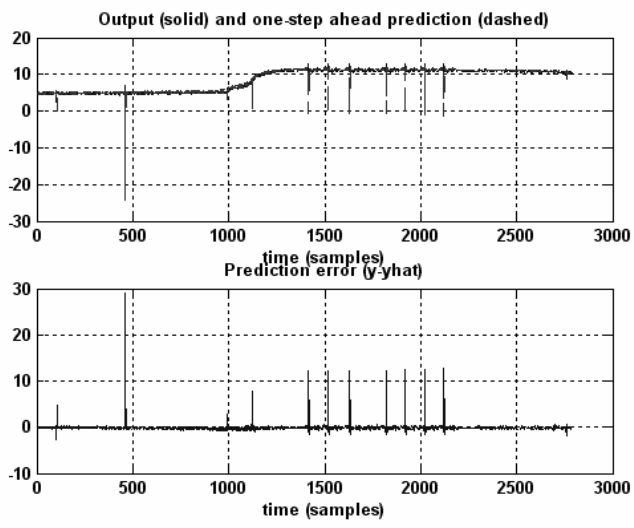

Figure 26: Performance of Prediction error of experimental $\mathrm{pH}$ process using NARX structure

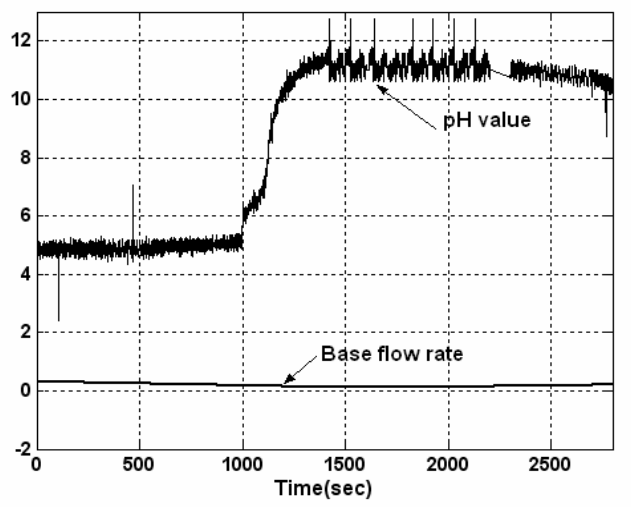

Figure 23: Testing data from Experimental Work

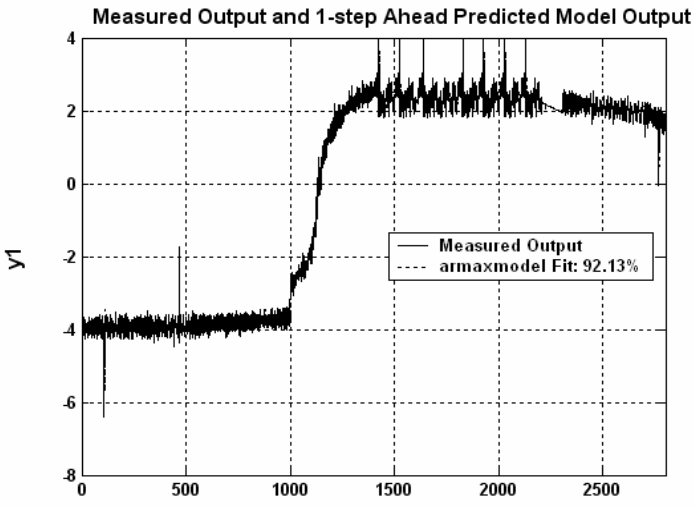

Figure 25: Validation of the ARMAX structure for Experimental $\mathrm{pH}$ process
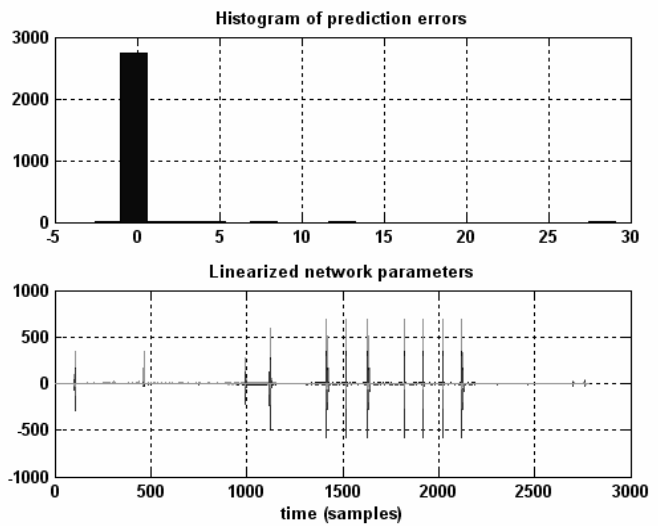

Figure 27: Histogram of prediction errors and linearized network parameters of experimental data using NARX structure 

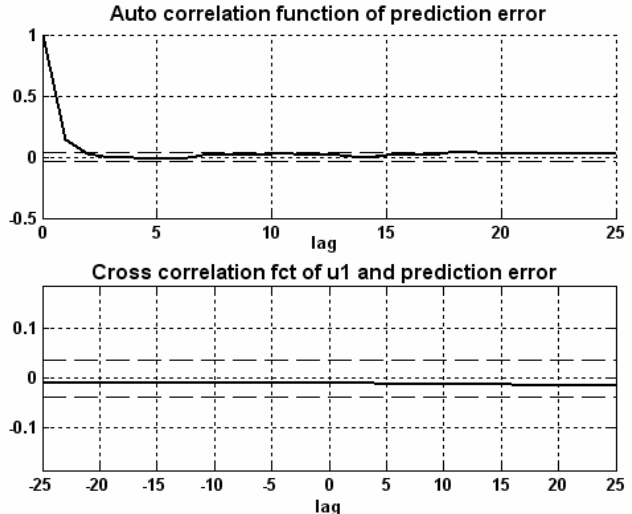

Figure 28: Auto-correlation and cross-correlation function for experimental data using NARX structure

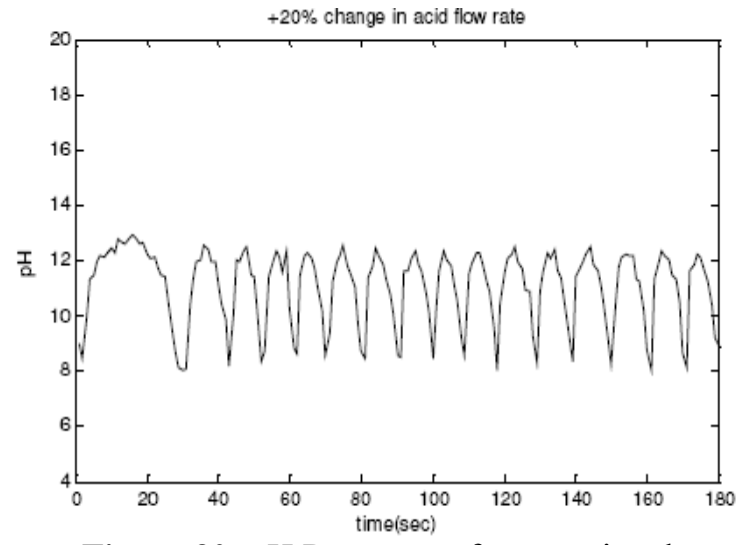

Figure 30: $\mathrm{pH}$ Response of conventional PI controller (MSE 17.01)

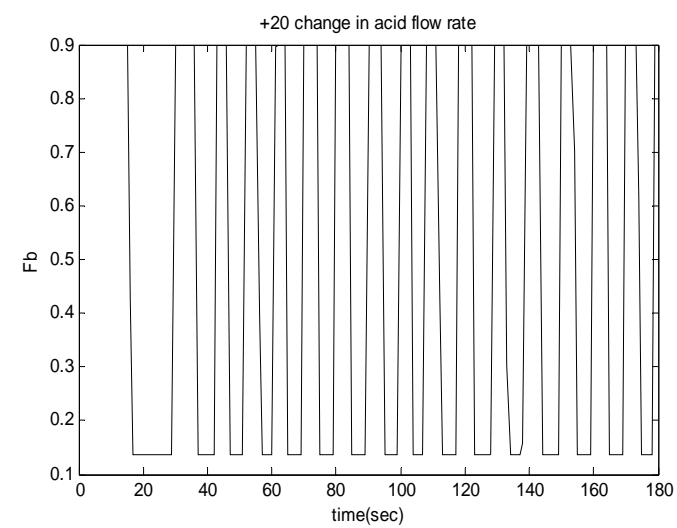

Figure 32: Response of base flow rate using conventional PI controller

\section{CONCLUSION}

The $\mathrm{pH}$ control is quite difficult due to nonlinearity of the neutralization process. This process requires good control to overcome the load disturbances. This paper has demonstrated how a

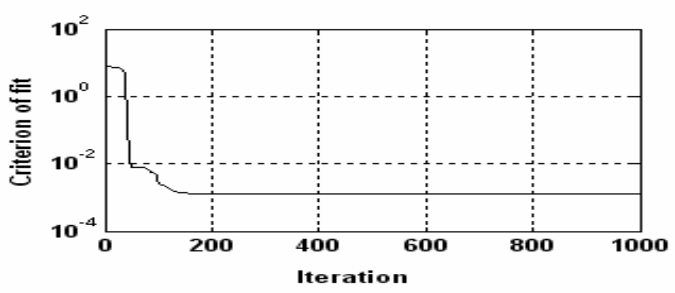

Figure 29: Fitness curve for real data using NARX structure

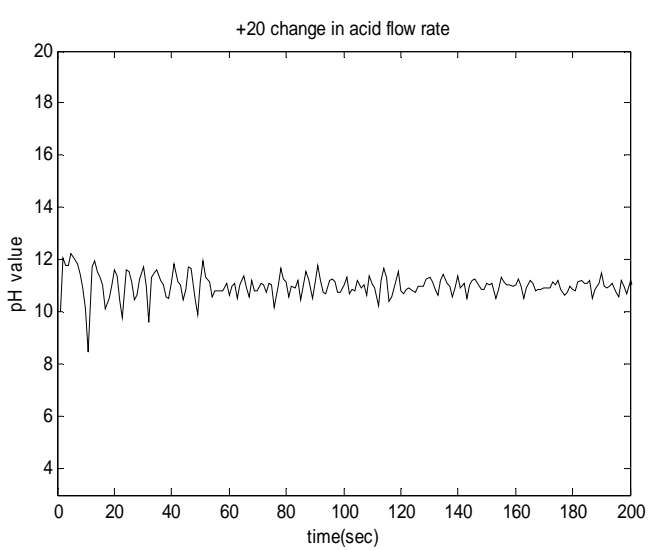

Figure 31: $\mathrm{pH}$ Response of PI controller using GA (MSE 0.1817)

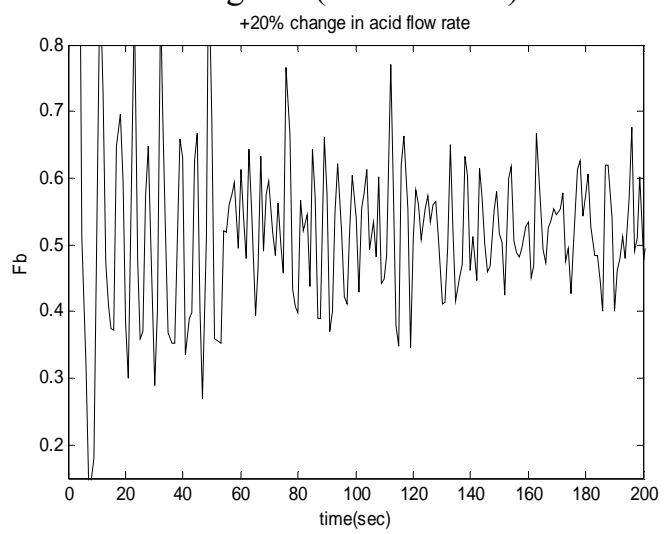

Figure 33: Response of base flow rate using GA tuned PI controller after identification

Genetic Algorithm based $\mathrm{pH}$ process can be used for optimum control by parameter estimation of ANN. The complete methodology is presented, focusing on each part of the adaptive system. The simulation results show the capability of the ANN system to identify and the GA system to adapt the controller to 
dynamic plant characteristic changes in the $\mathrm{pH}$ process. Experimental results show that the proposed controller is able to tune the controller quickly and reduce the tracking error to zero, similar to simulation results.

\section{ACKNOWLEDGEMENT}

This work was performed at the Advanced Process Control Laboratory, Department of Chemical Engineering, National Institute of Technology, Trichy.

\section{REFERENCES}

Astrom, K. J. and Hagglund T., The future of PID control, Control Engineering Practice, 9, No-11, 1163-1175 (2001).

Dangprasert, P. and Avatchanakorn V., Genetic Algorithms Based Self-Tuning Regulator, IEEE International Conference on Evolutionary Computation, 1, 444-449 (1995).

Dionisio, S. and Pinto P., Genetic algorithm based system identification and PID tuning for optimum adaptive control, International Conference on Advanced Intelligent Mechatronics, California, 801-806 (2005).

Goldberg, D. E., Genetic Algorithms in Search Optimization and Machine Learning, Addison Wesley (1989).

Kristinsson, K. and Dumont G. A, System Identification and Control Using Genetic Algorithms, IEEE Trans. System, Man and Cybernetics, 22, No-5, 1033-1046 (1992).

Kulkarni, B. D. and Deshpande P. B., Nonlinear pH control, Chem. Eng. Science, 46, 995-1003 (1991).

Lennart Ljung, System Identification - Theory for the User, 2nd Ed, PTR Prentice Hall, Upper Saddle River, N. J. (1999).
Lu, S. and Basar T., Genetic algorithms-based identification, IEEE Inter. Conf. System, Man and Cybernetics, 1, 22-25 (1995).

Manfred Morari and Evanghelos Zufiriou, Robust Process Control, Prentice-Hall, NJ, 1987.

McAvoy, T. J. and Hsu, E., Dynamics of $\mathrm{pH}$ in Controlled Stirred Tank Reactor, Ind. Eng. Chem. Process Des. Dev., 1, No-68, 114-120 (1972).

Mwembeshi, M. M. and Kent C. A., A genetic algorithm based approach to intelligent modelling and control of $\mathrm{pH}$ in reactors, Computers \& Chemical Engineering, 28, No-9, 1743-1757 (2004).

Narendra, K. S. and Parthasarathy K., Identification and control of dynamic systems using neural networks, IEEE Trans Neural Networks, 1, 4-27 (1990).

Passino, K. M., Towards bridging the perceived gap between conventional and intelligent control, Intelligent Control: Theory and applications, pp.1-27 (1996).

Rad, B. and Lo W.L., Self-tuning PID controller using Newton-Raphson search method, Trans. on Industrial Electronics, 44, No-5, 717-725 (1997).

Schei, T. S., Automatic tuning of PID controllers based on transfer function estimation, Automatica, 30, No-12, 1983-1989, (1994).

Shinskey, F. G., Process Control System: Application, Design and Tuning, McGraw-Hill, 4th Ed, 1996.

Timothy Ross, Fuzzy Logic with Engineering Application, Tata McGraw Hill Inc., (1995).

Vlachos C., Williams D. and Gomm J. B., Genetic approach to decentralized PI controller for multivariable processes, Proc. of IEE Control Theory Applications, 146,No-1, 58-64, (1999).

Wasserman, P. D., Neural Computing: Theory and Practice, New York, Van Nostrand Reinhold, (1989).

Zibo, Z. and Naghdt F., Application of genetic algorithms to system identification, IEEE Inter. Conf. on Evolutionary Computation,2,777-782, (1995). 